Document downloaded from:

http://hdl.handle.net/10251/103990

This paper must be cited as:

Prevot, AB.; Baino, F.; Fabbri, D.; Franzoso, F.; Magnacca, G.; Nistico, R.; Arqués Sanz, A. (2017). Urban biowaste-derived sensitizing materials for caffeine photodegradation.

Environmental Science and Pollution Research. 24(14):12599-12607. doi:10.1007/s11356016-7763

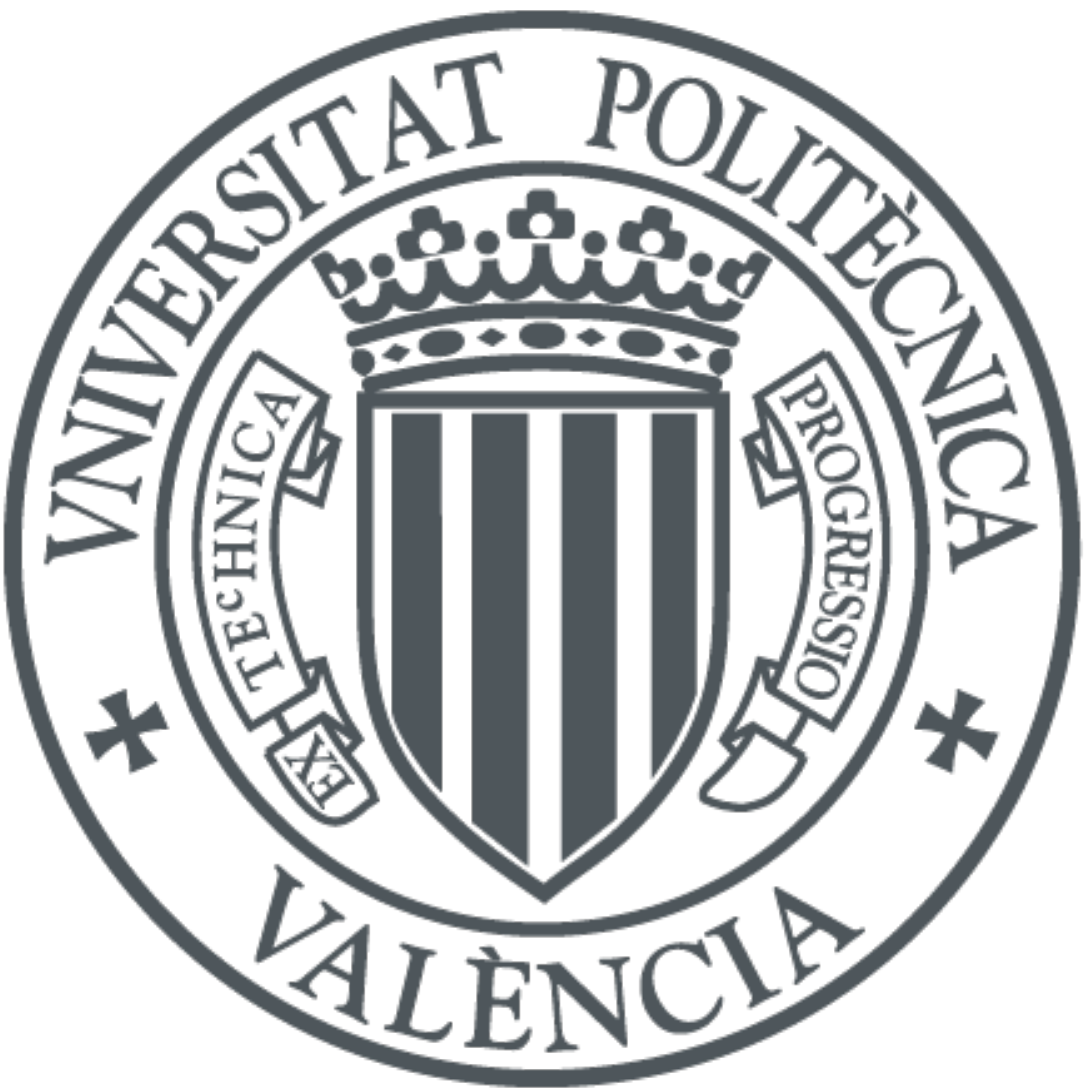

The final publication is available at

https://doi.org/10.1007/s11356-016-7763-1

Copyright Springer-Verlag

Additional Information 


\title{
Urban biowaste-derived sensitizing materials for caffeine photodegradation
}

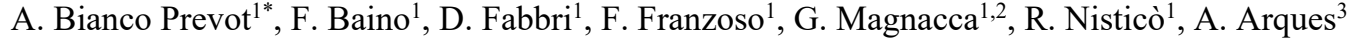 \\ ${ }^{1}$ Università degli Studi di Torino, Dipartimento di Chimica and ${ }^{2}$ NIS Centre, Via Giuria 7, Torino, Italy \\ ${ }^{3}$ Universitat Politècnica de València, Dpto de Ingeniería Textil y Papelera, Plaza Ferrándiz y Carbonell s/n, Alcoy,Spain \\ *alessandra.biancoprevot@unito.it \\ $+390116705292$
}

\begin{abstract}
Caffeine photosensitized degradation has been studied in the presence of bio-based materials derived from urban biowaste after aerobic ageing. A peculiar fraction (namely BBSs), soluble in all the $\mathrm{pH}$ range, has been used as photosensitizing agent. Several caffeine photodegradation tests have been performed and positive results have been obtained in the presence of BBSs and $\mathrm{H}_{2} \mathrm{O}_{2}$, without and with additional Fe(II) (photo-Fenton-like process). Moreover hybrids magnetiteBBSs nanoparticles have been synthesized and characterized, in order to improve the sensitizer recovery and re-use after the caffeine degradation. In the presence of such nanoparticles and $\mathrm{H}_{2} \mathrm{O}_{2}$ and $\mathrm{Fe}(\mathrm{II})$, the complete caffeine degradation has been attained in very short time. Both homogeneous and heterogeneous processes were run at $\mathrm{pH}=5$, milder condition compared to the classic photo-Fenton process.
\end{abstract}

Keywords: caffeine photodegradation; bio-based substances; Fenton; photo-Fenton, magnetic nanoparticles; urban waste

\section{Introduction.}

In recent years the organic fraction of urban waste (urban bio-waste, UBW) has attracted the attention of scientists as well as Institutions and policy makers, driven by the need of reducing society climate footprint and other environmental burdens, of achieving a more secure supply of resources and of boosting the bio economy (O'Callaghan 2016 and references therein). UBW can indeed be considered not only as a possible source of energy and/or fuel, rather as feedstock for the production of chemicals, inside the so-called biorefinery, a facility that integrates physical, chemical, biochemical and thermochemical processes to efficiently convert biomass feedstocks. In this respect, biorefinery allows the valorization of bio-waste beyond energy applications.(Satchatippavarn et al. 2016;Gonzalez-García et al. 2016; Girotto et al. 2015).

The feasibility of bio-waste upgrading has been investigated through several European projects (Biochemenergy, Biocoreeurope, biowaste4sp, eurobioref). Among different approaches, in the present work we focused on waste-derived biobased substances isolated from UBW, anaerobically and/or aerobically treated, following the findings of Montoneri et al. (Montoneri et al. 2011; Montoneri et al. 2013). After isolation the bio-based substances (hereinafter BBS) have been characterized under structural and physico-chemical point of view, and their similarity with soil humic substances has been evidenced, as reported in details in previous publications (Montoneri et al. 2011). Basically, BBS are supramolecular aggregates with a complex lignin-derived structure containing several functionalities (namely, acid and basic functional groups bonded to aromatic and aliphatic chains); moreover the presence of both hydrophilic and hydrophobic moieties 
confers to BBS amphiphilic properties. Figure 1 is a schematic representation of the BBS isolation process and of the state of the art concerning their applications.

Among the wide range of BBS applications, the "waste for cleaning waste" approach has deserved great attention (Avetta et al. 2013). It consists in the use of BBS as chemical auxiliaries to drive photochemical degradation of pollutants. Actually it has been already demonstrated the capability of compounds analogous to BBS to sensitize the photodegradation of phenols, azo-dyes and emerging pollutants through different mechanisms: i) direct sensitization, upon UV-VIS irradiation, by means of reactive oxygenated species production or excited triplet state formation; ii) auxiliaries in mild photo-Fenton like processes (Canonica et al. 1995; Wenk et al. 2011; Bianco Prevot et al. 2011; Gomis et al. 2015; Carlos et al. 2012).

Recently, attention has been paid to the heterogeneization of the BBS, by synthesizing hybrid magnetite-BBS nanoparticles (Magnacca et al. 2014). Magnetite $\left(\mathrm{Fe}_{3} \mathrm{O}_{4}\right)$ nanoparticles represent promising candidates as catalysts for AOP due to their benign nature and low-cost; furthermore, their properties can be tailored according to their purpose. Finally, the nanoparticles surface can be functionalized with a wide variety of non-toxic materials containing (photo)active groups that act both as stabilizers against the magnetite oxidation and also as catalysts (Nadejde et al. 2015; Nadejde et al. 2015a). In addition magnetite-organic hybrid materials are easy to be recovered from the solutions after their purification treatment (Munoz et al. 2015).

In the present work, a peculiar BBS fraction (namely BBSs) has been studied as photosensitizing agent; BBSs is soluble in all the $\mathrm{pH}$ range, whereas BBS typically precipitate at $\mathrm{pH}$ lower than about 3; under the solubility point of view BBSs can be considered more similar to the fulvic fraction of the natural organic matter, while BBS are similar to the humic one. Data previously obtained about BBSs allow to hypothesize lower dimension compared to BBS, reduced aromaticity and higher concentration of carboxilic groups, thus yielding to higher hydrophilicity (Avetta et al. 2015). Both homogeneous and heterogeneous sensitized caffeine photodegradation have been studied; the present research includes therefore also the synthesis and characterization of hybrid magnetite-BBSs nanoparticles (hereinafter BBSs-NPs). The present research aims therefore to gain further insight into BBS application, with particular attention to the photodegradation of the so-called emerging pollutants present in aqueous solution. In particular caffeine, a psychoactive substance, widely consumed either for beverages or for pharmaceuticals and personal care products, has been chosen as representative compound. In fact, it has been detected in natural water streams (Metcalfe et al. 2003) over many different countries, being not fully degraded in biological water treatment plants. Moreover caffeine has been considered as a chemical marker for surface water pollution (Buerge et al. 2003). Caffeine degradation studies are already reported in literature using $\mathrm{TiO}_{2}$ and photo-Fenton approaches under solar conditions (Bernabeu et al. 2011; Klamerth et al. 2010; Klamerth et al. 2009; Klamerth et al. 2010a), and the caffeine photolysis was also studied in the presence of added fulvic acid (Jacobs et al. 2012).

\section{Materials and methods}

\section{Reagents}

Caffeine, $\mathrm{CH}_{3} \mathrm{OH}, \mathrm{NaOH}, \mathrm{NH}_{4} \mathrm{OH}$ and $\mathrm{FeCl}_{3}$ where purchased from Aldrich; $\mathrm{CH}_{3} \mathrm{CN}$ and $\mathrm{HCl}$ were purchased from Merck; $\mathrm{H}_{2} \mathrm{O}_{2}, \mathrm{HClO}_{4}$ and $\mathrm{FeSO}_{4} \times 7 \mathrm{H}_{2} 0$ were purchased from Panreac. All reagents were used without further purification. For the preparation of BBSs solution, the starting material called BBS-GC, isolated from urban biowastes sampled from the process lines of ACEA Pinerolese Industriale S.p.A. waste treatment plant in Pinerolo (Italy), has been chosen. The urban biowaste was obtained in the compost production section, from urban public park trimming and home gardening residues aged for more than 180 days (green compost, GC). The process is an advanced system that comprises specific 
technological facilities, developed by ACEA Pinerolese Industriale S.p.A, and under European validation. Isolation of BBS-GC was performed following a previously reported procedure (Nisticò et al. 2015). The BBSs fraction has been isolated in solution, after precipitation of the insoluble fraction at $\mathrm{pH}=1.5$ with $\mathrm{HCl}$.

Hybrid BBSs-NPs have been synthesized following a procedure reported in the literature (Magnacca et al. 2014, Cesano et al. 2015). In details, $3.7 \mathrm{~g}$ of $\mathrm{FeCl}_{3}$ and $4.17 \mathrm{~g}$ of $\mathrm{FeSO}_{4} \cdot 7 \mathrm{H}_{2} \mathrm{O}$ (molar ratio $\mathrm{Fe}(\mathrm{III}) / \mathrm{Fe}(\mathrm{II})=1.5$ ) were dissolved in 100 $\mathrm{mL}$ of deionized water and heated up to $90^{\circ} \mathrm{C}$. Once the temperature was reached, two solutions were added in sequence: a) $10 \mathrm{~mL}$ of 25 vol.\% ammonium hydroxide, and b) $50 \mathrm{~mL}$ of a previously prepared BBSs-GC aqueous solution. The mixture was mechanically stirred at $90^{\circ} \mathrm{C}$ for $30 \mathrm{~min}$ and then cooled down to room temperature. In this way a dispersion of BBSs-GC-NPs has been directly obtained in a one-step process by co-precipitation method. Such dark-brown solutions were purified by washing twice with deionized water, deposited onto glass Petri dishes, and oven-dried at $80^{\circ} \mathrm{C}$ overnight.

\section{Instrumental aspects}

Fourier transform infrared (FTIR) spectra were recorded in transmission mode using the sample dispersed in $\operatorname{KBr}(1: 20$ weight ratio) by means of a Bruker Vector 22 spectrophotometer equipped with Globar source, DTGS detector, and working with 128 scans at $4 \mathrm{~cm}^{-1}$ resolution in the $4000-400 \mathrm{~cm}^{-1}$ range.

X-ray diffraction (XRD) patterns were obtained by using an X'Pert PRO MPD diffractometer from PANalytical, in BraggBrentano geometry in a flat sample-holder, equipped with $\mathrm{Cu}$ anode, working at $40 \mathrm{kV}$ and $30 \mathrm{~mA}$. The acquisition was performed in a $0.002^{\circ}$ interval steps, with $45 \mathrm{~s} \mathrm{step}^{-1}$ in order to improve the signal to noise ratio. Thermo-gravimetric analyses (TGA) were carried out by means of TGA Q600 (TA Instruments). The powders (ca. $30 \mathrm{mg}$ ) were placed in an open alumina pan and heated from 40 to $800^{\circ} \mathrm{C}$ at the rate of $10^{\circ} \mathrm{C} \mathrm{min}^{-1}$ under either nitrogen or air atmosphere. In order to calculate the organic fraction in the BBSs-NPs, the following equation was applied to the TGA results carried out in oxygen:

$$
\text { wt. } \% \text { om }=\left[\mathrm{wt} . \%(\mathrm{~T}){ }_{150^{\circ} \mathrm{C}}\right]-\left[\mathrm{wt} . \%(\mathrm{~T}){ }_{500^{\circ} \mathrm{C}}\right](1)
$$

Where: wt. $\%$ om is the content of organic matter, wt. $\%\left(\mathrm{~T}_{150^{\circ} \mathrm{C}}\right)$ is the initial dried mass of the sample, and wt. $\%\left(\mathrm{~T}_{500^{\circ} \mathrm{C}}\right)$ is the sample mass before any Fe-involved transition.

Magnetization measurements were carried out with a LakeShore 7404 vibrating sample magnetometer. The hysteresis loop of the samples was registered at RT as the magnetic field was cycled between -20000 and 20000 Gauss.

Total organic carbon (TOC) content was determined by means of a ShimadzuTOC-VCSH analyzer. Measurements of pH were performed using a Methohm $713 \mathrm{pH}$-meter equipment with a combined glass electrode. $\mathrm{The}_{2} \mathrm{H}_{2} \mathrm{O}_{2}$ determination was performed with a Merck colorimetric kit.

ICP-OES, Perkin Elmer, Optima 5300 DV with cross-flow nebulizer was used for metal (iron) determination, with the following set-up: Argon C-45 (99.995\% purity). $1300 \mathrm{~W}$, gas plasma $=15 \mathrm{~L} / \mathrm{min}$, auxiliary gas $=0.2 \mathrm{~L} / \mathrm{min}$, nebulizing gas $=0.8 \mathrm{~L} / \mathrm{min}$, sampling flow rate $=1.1 \mathrm{~mL} / \mathrm{min}$.

UV-VIS spectroscopic measurements were made using Cary 100 Scan (Varian) spectrophotometer.

Caffeine was determined with a UHPLC Flexar FX-10, equipped with a S200 KIT-1022 PLUS autosampler, two Flexar FX 10 UHP PUMP MASTER pumps, FL degaser and a UV/VIS KIT-UHPLC detector. A Brownlee Analytical DB C18 column (30 mm length, i.d. $2.1 \mathrm{~mm}$, particle diameter $1.9 \mu \mathrm{m}$ ) was used. $\mathrm{CH}_{3} \mathrm{CN}(\mathrm{ACN})$ and water were used as eluent $\mathrm{A}$ and $\mathrm{B}$ respectively, upon the following elution conditions: $\mathrm{t}=0.0 \mathrm{~min}, \mathrm{~A}: 10 \% ; \mathrm{t}=2.5 \mathrm{~min}, \mathrm{~A}: 70 \% ; \mathrm{t}=4.0 \mathrm{~min}, \mathrm{~A}$ : $3 \%$. Eluent flow $=0.3 \mathrm{~mL} / \mathrm{min}$; detection wavelength $=205 \mathrm{~nm}$.

\section{Irradiation devices}

Two different irradiation devices have been used throughout the work: 
i) open solar simulator ORIEL INSTRUMENTS 81160 equipped with a Xenon lamp (300 W), whose emission spectrum closely matched the solar one; a cut off pyrex filter was employed to filter the small fraction of photons emitted below $300 \mathrm{~nm}$. Experiments were performed on $250 \mathrm{ml}$ of solution, kept under magnetic stirring. Water was eventually added to compensate for the evaporation loss.

ii) Cylindrical Pyrex reactor equipped with a Xenon UV-TXE150 PESCHL ADVANCED lamp (150 Watt). Experiments were performed on $250 \mathrm{ml}$ of solution under continuous oxygen bubbling ( $1 \mathrm{~L} / \mathrm{min}$ flow rate).

The first set-up was used in the BBS mediated photo-Fenton, while the second one was employed when nanoparticles were involved in order to allow air bubbling into the sample to keep the particles in suspension.

\section{Results and discussion}

For the experiments performed with BBSs, the TOC has been taken as reference parameter in order to compare experiments run in different conditions; the organic C content of BBSs was found to correspond to 9.3 wt.\%.

\section{BBSs-NPs characterization}

In order to better understand the chemical composition of such BBSs-NPs, a wide physico-chemical characterization has been realized and data summarized in Figure 2.

Infrared spectroscopy was used to investigate the presence of BBS in BBSs-NPs and the spectra are reported in Figure 2A. In particular, the presence of magnetite phase is highlighted by signals at 575 and $620 \mathrm{~cm}^{-1}$ due to Fe-O stretching vibrations, the presence of BBSs is confirmed by the BBSs-carboxylate stretching mode at ca. $1600 \mathrm{~cm}^{-1}\left(\mathrm{Magnacca}^{\mathrm{et}}\right.$ al. 2014), the signal at $1120 \mathrm{~cm}^{-1}$ is due to $\mathrm{C}-\mathrm{O}$ stretching mode of organic matter adsorbed onto the iron oxide surface (i.e. polysaccharides and other BBS-derived substances) (Ou et al. 2009) and the very sharp band at $1400 \mathrm{~cm}^{-1}$ witnessed the interaction between BBSs-carboxylate functionalities and the iron oxide surface (Ou et al. 2009).

Thermogravimetric analyses have been performed in order to assess the BBSs-NPs stability as well as the organic matter content. Figure 2B reports the profiles obtained working under air (oxidant) or nitrogen (inert/reducing) atmosphere. The thermal profile of BBSs-NPs treated in air (black curves in Figure 2B) shows three weight losses, as clearly evidenced by the DTG curve: the first one, in the range $30-150^{\circ} \mathrm{C}$, corresponding to water evaporation; the second one, complex, in the range $150-500^{\circ} \mathrm{C}$, corresponding to BBSs oxidation to $\mathrm{CO}_{2}$ and the third one, at temperatures higher than $600^{\circ} \mathrm{C}$, that can be assigned to the magnetite to hematite transition. In spite of the Curie temperature reported for this transition (i.e. $580^{\circ} \mathrm{C}$ ), a peak is observed at $\mathrm{T}>600^{\circ} \mathrm{C}$, suggesting a protection role of the organic matter towards magnetite oxidation, since the phase transformation occurs only after the complete removal of the organic matter. Vice versa, when TGA was run under $\mathrm{N}_{2}$ atmosphere (red curves in Figure 2B), the main differences concerned the transformation of the BBSs, yielding to the formation of a carbonaceous residue, and the transition magnetite to wustite, a diamagnetic iron oxide $(\mathrm{FeO})$, at $\mathrm{ca} .720^{\circ} \mathrm{C}$. Since at the end of TGA analysis the material is still magnetic, it can be hypothesized that wustite disproportionates giving magnetite and zero valent iron (both magnet-sensitive iron-containing phases) (Cesano et al. 2015).

Basing on TGA experiments performed on BBSs-NPs in oxygen flux, the amount of BBSs present in the hybrid BBSsNPs can be estimated by means of weight loss in the range $150-500^{\circ} \mathrm{C}$, following the Equation 1 . The calculated amount corresponded to $14.2 \mathrm{wt} \% \%$ of organic matter.

The presence of magnetite forming the BBSs-NPs was identified through XRD (see Figure 2C). All the crystalline reflections in the figure at $2 \theta=30.1^{\circ}(220), 35.4^{\circ}(311), 43.0^{\circ}(400), 53.9^{\circ}(422) 57.2^{\circ}(511)$, and $62.6^{\circ}(440)$ are consistent with the neat magnetite phase. No relevant reflections are expected from BBSs since its XRD pattern presents only one broad amorphous contribution centered at ca. $2 \theta=25^{\circ}$ and few negligible signals (Franzoso et al. in preparation). 
Extra peaks are due to by-products (mainly ammonium-containing salts) of the coprecipitation reaction for the magnetite synthesis.

The magnetic properties of both BBSs-NPs and neat magnetite are reported in Figure 2D. In general, both samples reveal superparamagnetic behaviors, with negligible remanence and very low coercitivity $(<10 \mathrm{G})$. The values of saturation magnetization of BBSs-NPs was $47 \mathrm{emu} \mathrm{g}^{-1}$, slightly lower than neat magnetite $\left(64 \mathrm{emu} \mathrm{g}^{-1}\right)$. This behavior suggests a different amount of magnetite per gram of sample due to the presence of the BBS covering shell (Cesano et al. 2015; Franzoso et al. in preparation).

\section{Caffeine photodegradation. \\ BBSs}

A previous study reported in the literature showed a negligible caffeine photodegradation ( $5 \%$ of caffeine abatement after 8 hours irradiation) due only to light irradiation when using the same experimental set-up(Gomis 2014).

In the present research caffeine has been firstly irradiated for three hours in the presence of BBSs at a concentration corresponding to $5 \mathrm{mg} \mathrm{L}^{-1}$ of organic $\mathrm{C}$ (about $54 \mathrm{mg} \mathrm{L}^{-1} \mathrm{BBSs}$ ), at $\mathrm{pH}=5.0$. As can been observed in Fig. 3 the abatement of caffeine was negligible after 2 hours of irradiation.

Further experiments have been performed in the same experimental conditions but adding $\mathrm{H}_{2} \mathrm{O}_{2} 7.0 \times 10^{-4} \mathrm{M}$. This is the stoichiometric amount of hydrogen peroxide required to mineralize the caffeine present in the sample; under these conditions, $85 \%$ of caffeine abatement was attained after two hours of irradiation.

As it clearly appears in the Fig.3, the irradiation of caffeine solution in the presence of the $\mathrm{H}_{2} \mathrm{O}_{2}$ alone, in the absence of BBSs, yields to a worst degradation efficiency, underlying a synergistic effect of $\mathrm{H}_{2} \mathrm{O}_{2}$ and BBSs on the process. It could be hypothesized that BBSs either sensitizes the $\mathrm{OH}$ radicals generation from $\mathrm{H}_{2} \mathrm{O}_{2}$ and/or initiate a photo-Fenton-like process due to presence of iron in the BBSs structure (Montoneri 2011).

Based on these results and on previously reported evidences of the capability of bio-based substances to complex iron ions yielding to experimental conditions similar to the ones applied in photo-Fenton process (Pignatello 2006), further experiments have been performed adding iron salts. It is worth to be noticed that all the experiments have been run at $\mathrm{pH}=5.0$, whereas lower $\mathrm{pH}$ values are usually required as optimum conditions, due to the low solubility of $\mathrm{Fe}(\mathrm{III})$ at mild $\mathrm{pH}$. This $\mathrm{pH}$ has been chosen because in previous papers it was determined as the highest value where photo-Fenton can be run in the presence of BBS with an acceptable loss of efficiency, as $\mathrm{pH}$ closer to neutrality resulted to be inconvenient (Gomis et al., 2015).

Figure 4 shows the results obtained by irradiating the caffeine aqueous solution in the presence of BBSs, $7.0 \times 10^{-4} \mathrm{M}$ of $\mathrm{H}_{2} \mathrm{O}_{2}$ and $5.0 \mathrm{mg} \mathrm{L}^{-1}$ of $\mathrm{Fe}(\mathrm{II})$ at $\mathrm{pH}=5$. For the sake of comparison, the results obtained by operating in the dark, adopting the same experimental conditions are also reported.

It clearly appears that the addition of $\mathrm{Fe}(\mathrm{II})$ induces both Fenton and photo-Fenton-like degradation processes, yielding to the $40 \%$ and to the $80 \%$ of caffeine disappearance, respectively, after 15 minutes of reaction. It is interesting to note, that the initial reaction rate is similar in both cases (Fenton process) but after 2 minutes, the Fenton process results clearly slower than photo-Fenton. $\mathrm{pH}$ modification was negligible along the experiment, as final values were systematically

\section{above 4.5 .}

The effect of iron concentration has been explored for the photo-Fenton-like process; experiments results are shown in Figure 5.

Only in the presence of $\mathrm{Fe}(\mathrm{II})$ at 4 and $5 \mathrm{mg} \mathrm{L}^{-1}$, after 5 min of irradiation a dark precipitate has been observed, probably due to iron oxides precipitation. Compared to the caffeine degradation performed in the presence of $\mathrm{H}_{2} \mathrm{O}_{2}$ alone, the 
addition of $\mathrm{Fe}$ (II) starts to affect the degradation rate at concentration higher than $2 \mathrm{mg} \mathrm{L}^{-1}$. Under the applicative point of view, the gain in terms of degradation rate upon addition of iron salt, cheap and non-toxic substance, compensates the cost increase. However, further addition of this metal is not always convenient, as it is limited by legislation.

In the presence of $5 \mathrm{mg} \mathrm{L}^{-1}$ of added $\mathrm{Fe}(\mathrm{II})$ the effect of $\mathrm{pH}$ has also been checked by performing several experiments in the $\mathrm{pH}$ range from 2.8 to 5.0 and the best performances have been obtained at $\mathrm{pH}=3.9$ that is probably the best compromise between reactive species production and $\mathrm{Fe}(\mathrm{II})$ stabilization by BBSs (Figure $1 \mathrm{~S}$ in the supplementary material). It is interesting to note, that the modification of the optimum $\mathrm{pH}$ to higher values, might involve a modification of the mechanism, as already observed (Gomis et al. 2015). However, the complexity of the system makes it difficult to find clear evidence for this mechanistic issue.

The BBSs concentration has then be decreased down to $0.9 \mathrm{mg} \mathrm{L}^{-1}$ as organic $\mathrm{C}$; in the absence of added iron some degradation of caffeine was observed. This could be due attributed to two different reasons: a) the photosensitizing effect of BBS that is able to catalyze decomposition of hydrogen peroxide into OH radicals and b) more likely, there is some amount of iron in SBO composition (ca. $0.7 \% \mathrm{w} / \mathrm{w}$ ) that is able to drive at certain extent a photo-Fenton process (Gomis et al., 2013). However, under those conditions caffeine degradation efficiency was worst, while it increased in the presence of iron (Figure 6); this evidence allows to hypothesize that, in the presence of added iron, the main effect of BBSs addition stays in its capability to stabilize iron ions in solution at mild pH, allowing a Fenton-like process to take place. In this case the minimum amount of added BBSs, able to stabilize iron ions in solution, reduces the competition for light harvesting; on the opposite side, if the photosensitization is directly related to reactive species production by irradiated BBSs, an increase in BBSs concentration favors the process. Furthermore, BBS also plays a competitive role for $\mathrm{H}_{2} \mathrm{O}_{2}$ which could be expected to be more significant in the case of photo-Fenton process, which is more efficient than BBs sensitization.

Regarding to the environmental problems associated to the addition of BBS to the effluent, previous results showed that the toxicity of these substances at the concentration employed in this paper (a few $\mathrm{mg} \mathrm{L}^{-1}$ ) is negligible according to different bioassays (Gomis et al, 2015b). Hence, although it could be a concern if the final purpose is its use as drinking water, this should not be a problem when discharged in ecosystems, because of its biocompatibility and similar characteristics with humic substances that constitute the major fraction of natural organic matter.

\section{BBSs-NPs}

In order to study the behavior of BBSs-NPs for caffeine photodegradation, a reactor allowing the suspension stirring with air bubbling instead of magnetic stirring has been employed. Preliminarily, the absence of caffeine direct photolysis has been checked. No caffeine degradation has been observed in the presence of $200 \mathrm{mg} \mathrm{L}^{-1}$ of BBSs-NPs under light irradiation. On the opposite, caffeine degradation was attained adding hydrogen peroxide or, with hydrogen peroxide and $\mathrm{Fe}(\mathrm{II})$, both in the dark and under light irradiation. Surprisingly, in these two last cases a very high efficiency has been reached. To explain this odd result, the stability of BBSs-NPs has been checked and a release of about $3 \mathrm{mg} \mathrm{L}^{-1}$ of organic $\mathrm{C}$ has been measured after 1 hour of irradiation of $200 \mathrm{mg} \mathrm{L}^{-1}$ of BBSs-NPs. Unfortunately, the release of organic matter is not sufficient to explain the observed efficiency, since the homogeneous process is not as fast (see Figure 3), therefore other information need to be collected in the future. One hypothesis should be that the BBSs not only complex iron, but also favor accumulation of caffeine in the more hydrophobic environment, allowing caffeine to react in the vicinity of the nanoparticles, thus reducing the effect of diffusion and iron deactivation.

\section{Conclusions}


The obtained results show the viability of photodegradation of caffeine assisted by waste derived bio-based materials (BBSs). In particular, both homogeneous and heterogeneous systems are promising approaches to drive photo-Fenton processes under mild $\mathrm{pH}$, which results in an enhanced sustainability of the process. It can therefore be concluded that biowaste are worth to be considered as a green tool for the preparation of materials for water treatments. Indeed, the degradation mechanism of the process deserves further investigation.

\section{Acknowledgements}

This work was realized with the financial support for academic interchange by the Marie Sklodowska-Curie Research and Innovation Staff Exchange project funded by the European Commission H2020-MSCA-RISE-2014 within the framework of the research project Mat4treaT (Project number 645551). Compagnia di San Paolo and University of Torino are gratefully acknowledged for funding Project Torino_call2014_L2_126 through "Bando per il finanziamento di progetti di ricerca di Ateneo - anno 2014" (Project acronym: Microbusters). Additionally, authors would like to acknowledge Dr. Flavio R. Sives (La Plata, Argentina) for magnetization measurements.

\section{References}

Avetta P, Bella F, Bianco Prevot A, Laurenti E, Montoneri E, Arques A, Carlos L, (2013) Waste cleaning waste: photodegradation of monochlorophenols in the presence of waste derived organic catalysts. ACS Sustainable Chemistry \& Engineering 1: 1545-1550

Avetta P, Berto S, Bianco Prevot A, Minella M, Montoneri E, Persico D, Vione D, Gonzalez MC, Mártire DO, Carlos L, Arques A, (2015) Photoinduced transformation of waste-derived soluble bio-based substances. Chemical Engineering Journal 274: 247-255

Bernabeu A, Vercher RF, Santos-Juanes L, Simón PJ, Lardín C, Martínez MA, Vicente JA, González R, Llosá C, Arques A, Amat AM, (2011) Solar photocatalysis as a tertiary treatment to remove emerging pollutants from wastewater treatment plant effluents. Catalysis Today 161: 235-240

Bianco Prevot A, Avetta P, Fabbri D, Laurenti E, Marchis T, Perrone DG, Montoneri E, Boffa V, (2011) Waste derived bio-organic substances for light induced generation of reactive oxygenated species. ChemSusChem, 4: 85-90

Buerge IJ, Poiger T, Müller MD, Buser HR, (2003) Caffeine, an anthropogenic marker for wastewater contamination of surface waters. Environmental Science and Technology, 37: 691-700

Canonica S, Jans U, Stemmler K, Hoigné J, (1995) Transformation kinetics of phenols in water: photosensitization by dissolved natural organic material and aromatic ketones. Environ. Sci. Technol. 29: 1822-1831

Carlos L, Martire DO, Gonzalez MC, Gomis J, Bernabeu A, Amat AM, Arques A, (2012) Photochemical fate of a mixture of emerging pollutants in the presence of humic substances. Water research 46: 4732-4740 
Cesano F, Fenoglio G, Carlos L, Nisticò R, (2015) One-step synthesis of magnetic chitosan polymer composite films. Applied Surface Science 345: 175-181.

Girotto F, Alibardi L, Cossu R, (2015) Food waste generation and industrial uses: A review. Waste Management 45: 3241

Gomis J, Vercher RF, Amat AM, Martire DO, González MC, Bianco-Prevot A, Montoneri E, Arques A, Carlos L (2013). Application of soluble bio-organic substances (SBO) as photocatalysts for wastewater treatment: sensitizing effect and photo-Fenton-like process. Catalysis Today, 209, 176-180.

Gomis J, Bianco Prevot A, Montoneri E, Gonzalez MC, Amat AM, Martire DO, Arques A, Carlos L, (2014) Waste sourced bio-based substances for solar-driven wastewater remediation: Photodegradation of emerging pollutants. Chemical Engineering Journal 235: 236-243

Gomis J, Carlos L, Bianco Prevot A, Teixeira ACSC, Mora M, Amat AM, Vicente R, Arques A, (2015a) Bio-based substances from urban waste as auxiliaries for solar photo-Fenton treatment under mild conditions: Optimization of operational variables. Catalysis Today $24039-45$

Gomis J, Gonçalves MG, Vercher RF, Sabater C, Castillo MA, Bianco Prevot A, Amat AM, Arques A. (2015b) Determination of photostability, biocompatibility and efficiency asphoto-Fenton auxiliaries of three different types of soluble bio-basedsubstances (SBO). Catalysis Today 252, 177-183

Gonzalez-García S, Gullon B, Rivas S, Feijoo G, Moreira MT, (2016) Environmental performance of biomass refining into high-added value compounds. Journal of Cleaner Production 120: 170-180

http://costeubis.org/ last accessed May 2016

Jacobs LE, Weavers LK, Houtz EF, Chin Y, (2012) Photosensitized degradation of caffeine: Role of fulvic acids and nitrate. Chemosphere 86: 124-129

Klamerth N, Miranda N, Malato S, Agüera A, Fernández-Alba AR, Maldonado MI, Coronado JM, (2009) Degradation of emerging contaminants at low concentrations in MWTPs effluents with mild solar photo-Fenton and $\mathrm{TiO}_{2}$. Catalysis Today 144: $124-130$

Klamerth N, Malato S, Maldonado MI, Agüera A, Fernández-Alba AR, (2010) Application of photo-Fenton as a tertiary treatment of emerging contaminants in municipal wastewater. Environmental Science and Technology, 44: 1792-1798

Klamerth N, Rizzo L, Malato S, Maldonado MI, Agüera A, Fernández-Alba AR, (2010a) Degradation of fifteen emerging contaminants at mu g L-1 initial concentrations by mild solar photo-Fenton in MWTP effluents. Water Research, 44: $545-554$ 
Magnacca G, Allera A, Montoneri E, Celi L, Benito DE, Gagliardi LG, Gonzalez MC, Mártire DO, Carlos L, (2014) Novel magnetite nanoparticles coated with waste-sourced biobased substances as sustainable and renewable adsorbing materials. ACS Sustainable Chem. Eng. 2 (6): 1518-1524

Metcalfe CD, Miao XS, Koenig BG, Struger J, (2003) Distribution of acidic and neutral drugs in surface waters near sewage treatment plants in the lower Great Lakes, Canada. Environmental Toxicology and Chemistry 22: 2881-2889

Montoneri E, Mainero D, Boffa V, Perrone DG, Montoneri C, (2011) Biochemenergy: a project to turn an urban wastes treatment plant into biorefinery for the production of energy, chemicals and consumer's products with friendly environmental impact. Int. J Global Environ Issues 11: 170-196

Montoneri E, Bianco Prevot A, Avetta P, Arques A, Carlos L, Magnacca G, Laurenti E, Tabasso S, (2013) Food wastes conversion to products for use in chemical and environmental technology, material science and agriculture. In: Kazmi A, Shuttleworth P (eds) The Economic Utilisation of Food Co-Products, Royal Society of Chemistry, pp.64-109

Munoz M, de Pedro ZM, Casas JA, Rodriguez JJ, (2015) Preparation of magnetite-based catalysts and their application in heterogeneous Fenton oxidation - A review. Applied Catalysis B: Environmental 176-177: 249-265.

Nadejde C. Neamtu M. Hodoroaba VD, Schneider RJ, Paul A, Ababei G, Panne U, (2015) Tannic acid- and natural organic matter-coated magnetite as green Fenton-like catalysts for the removal of water pollutants. J Nanopart Res 17: 476-486.

Nadejde C. Neamtu M. Hodoroaba VD, Schneider RJ, Paul A, Ababei G, Panne U, (2015a) Green Fenton-like magnetic nanocatalysts: Synthesis, characterization and catalytic application. Applied Catalysis B: Environmental 176-177: 667677

Nisticò R, Barrasso M, Carrillo Le Roux GA, Seckler MM, Sousa W, Malandrino M, Magnacca G, (2015) Biopolymers from composted biowaste as stabilizers for the green synthesis of spherical and homogeneously sized silver nanoparticles for textile application on natural fibers. ChemPhysChem 16: 3902-3909

O’Callaghan K, (2016) Technologies for the utilisation of biogenic waste in the bioeconomy. Food Chemistry 198: 2-11

Ou X, Chen S, Quan X, Zhao H, (2009) Photochemical activity and characterization of the complex of humic acids with iron(III). Journal of Geochemical Exploration 102: 49-55

Pignatello JJ, Oliveros E, Mackay A, (2006) Advenced oxidation processes for organic contaminant destruction based on the Fenton reaction and related chemistry. Critical Reviews in Environmental Science and Tecnology 36: 1-84

Satchatippavarn S, Martinez-Hernandez E, Hang P, Leach M, Yang A, (2016) Urban biorefinery for waste processing. Chemical Engineering Research and Design 107: 81-90 
Wenk J, Von Gunten U, Canonica S, (2011) Effect of dissolved organic matter on the transformation of contaminants induced by excited triplet states and the hydroxyl radical. Environ. Sci. Technol. 45: 1334-1340

http://www.biochemenergy.it/

www.biocore-europe.org, last accessed May 2016

www.biowaste4sp.eu, last accessed May 2016

www.eurobioref.org, last accessed May 2016 


\section{Figure captions}

Figure 1. Schematic representation of BBS isolation and their tested applications.

Figure 2 Physicochemical characterization of reference neat BBSs and BBSs-NPs. Panel A: Absorbance FTIR spectra in the $1800-400 \mathrm{~cm}^{-1}$ range relative to neat magnetite (A, black solid line), BBSs-NPs (B, red solid line), and neat BBS (C, red dotted line). The main relevant peaks are labeled. All spectra are collected in transmission mode through KBr pellets. Panel B: TG (solid line) and DTG (dotted lines) curves of BBSs-NPs heated either in air (black) or in nitrogen (red) atmosphere. Panel C: XRD patterns of the neat magnetite (black) and BBSs-NPs (red). The main reflections due to magnetite are highlighted and labeled. Panel D: Magnetization curves evaluation of neat magnetite (black) and BBSsNPs (red).

Figure 3 Relative caffeine concentration vs. irradiation time. Experimental conditions: caffeine $5 \mathrm{mg} \mathrm{L}^{-1}, \mathrm{pH}=5.0$. Legends: Blue diamonds: BBSs 5 mg L-1 (as organic C). Black triangles: $\mathrm{H}_{2} \mathrm{O}_{2} 7.0 \times 10^{-4} \mathrm{M}$. Red squares: $\mathrm{BBSs}^{2} \mathrm{mg} \mathrm{L}{ }^{-1}$ (as organic C), $\mathrm{H}_{2} \mathrm{O}_{2} 7.0 \times 10^{-4} \mathrm{M}$.

Figure 4 Relative caffeine concentration vs. contact time. Experimental conditions: caffeine $5 \mathrm{mg} \mathrm{L} \mathrm{L}^{-1}, \mathrm{pH}=5.0, \mathrm{BBSs} 5$ $\mathrm{mg} \mathrm{L}^{-1}$ (as organic C), $\mathrm{H}_{2} \mathrm{O}_{2} 7.0 \times 10^{-4} \mathrm{M}, \mathrm{Fe}(\mathrm{II}) 5 \mathrm{mg} \mathrm{L}^{-1}$. Legend: Blue triangles: Fenton experiments in the dark. Green triangles: photo-Fenton experiments under light irradiation.

Figure 5 Caffeine relative concentration vs. irradiation time. Experimental conditions: caffeine $5 \mathrm{mg} \mathrm{L} \mathrm{L}^{-1}, \mathrm{pH}=5.0$, BBSs $5 \mathrm{mg} \mathrm{L}^{-1}$ (as organic C), $\mathrm{H}_{2} \mathrm{O}_{2} 7.0 \times 10^{-4} \mathrm{M}$. Effect of the Fe(II) concentration. Legend: Black squares: Fe(II) 1 ppm. Red circles: Fe(II) 2 ppm. Blue up-triangles: Fe(II) 3 ppm. Dark cyan down-triangles: Fe(II) 4 ppm. Magenta squares: Fe(II) 5 ppm.

Figure 6. Caffeine relative concentration vs. irradiation time. Experimental conditions: caffeine $5 \mathrm{mg} \mathrm{L}^{-1}, \mathrm{pH}^{-1}=5.0, \mathrm{H}_{2} \mathrm{O}_{2}$ $7.0 \times 10^{-4} \mathrm{M}$. Red series: Solid squares, red solid line: BBSs $5 \mathrm{mg} \mathrm{L}^{-1}$ (as organic C); Open squares, dotted line: BBSs 0.9 $\mathrm{mg} \mathrm{L}^{-1}$ (as organic C). Green series: Fe(II) 5 ppm; Solid triangles, solid line: BBSs $5 \mathrm{mg} \mathrm{L}^{-1}$ (as organic C); Open triangles, dotted line: BBSs $0.9 \mathrm{mg} \mathrm{L}^{-1}$ (as organic C).

Figure 7. Caffeine relative concentration vs. irradiation time. Experimental conditions: caffeine $5 \mathrm{mg} \mathrm{L}^{-1}, \mathrm{pH}=5.0$. Blue diamonds: $\mathrm{H}_{2} \mathrm{O}_{2} 7.0 \times 10^{-4} \mathrm{M}$. Red squares: $\mathrm{H}_{2} \mathrm{O}_{2} 7.0 \times 10^{-4} \mathrm{M}$, BBSs-NPs $200 \mathrm{mg} \mathrm{L}{ }^{-1}$. Green solid triangles: $\mathrm{H}_{2} \mathrm{O}_{2} 7.0 \times 10^{-}$ ${ }^{4} \mathrm{M}$, BBSs-NPs $200 \mathrm{mg} \mathrm{L}^{-1}, \mathrm{Fe}$ (II) $5 \mathrm{mg} \mathrm{L}^{-1}$, photo Fenton experiments under light irradiation; Green open triangles: $\mathrm{H}_{2} \mathrm{O}_{2}$ $7.0 \times 10^{-4} \mathrm{M}$, BBSs-NPs $200 \mathrm{mg} \mathrm{L}^{-1}$, Fe(II) $5 \mathrm{mg} \mathrm{L}^{-1}$, Fenton experiments in the dark. 